\title{
Determination of Optimal Reaction Temperature and Hydrogen Amount for Propylene Polymerization by a Mathematical Model
}

\author{
G. H. Varshouee, ${ }^{a}$ A. Heydarinasab ${ }^{a^{*}}$ A. Vaziri,a \\ and S. M. Ghafelebashi Zarand ${ }^{b}$ \\ a Department of Petroleum and Chemical Engineering, Science and Research Branch, \\ Islamic Azad University, Tehran, Iran \\ b Polymer Group, Research and Technology, National Petrochemical Company, Tehran, Iran
}

\begin{abstract}
Regarding the complexity of Ziegler-Natta catalyst kinetics in polypropylene polymerization, so far, there is no adequate model to determine the best process conditions for predicting average molecular weight and dispersity as the most crucial final product properties index. Consequently, a validated model has been developed which describes the relationship between the kinetic model and the existing gap using the polymer moment balance approach. It was concluded that increasing reaction temperature and hydrogen amount are useful and improve the final product indices to a certain limit, but afterwards they have harmful effects on the indices.
\end{abstract}

\section{Keywords}

Mathematical modelling, propylene polymerization, optimization, population balance, average molecular weight, dispersity

\section{Introduction}

Polypropylene is nowadays one of the most widely used polyolefins, and its application is strongly influenced by the final product properties. In spite of about sixty years of Ziegler-Natta catalyst use for polypropylene production, the polymerization performance remains ambiguous and hazy due to the complexity of the catalyst kinetics. ${ }^{1-2}$

In practice, the polymer application is determined by certain crucial indices such as the number and weight average molecular weight $\left(\overline{M_{n}} \& \overline{M_{w}}\right)$ and dispersity $(\boxplus)$ as an indicator of molecular weight distribution. Since these indices of final product properties are highly dependent on the process variables, i.e., reaction temperature and hydrogen amount in the polymerization system, it is necessary to investigate how the process variables affect these final product properties indices. Accordingly, for designing a desired product, a mathematical model could be a worthy replacement for the conventional manner, i.e., experimental by trial and error. There is still a need for a validated mathematical model that would be able to predict these final product properties in a proper way. In view of the significance of these matters, few researchers have addressed these problems in a comprehensive and clarified manner, in particular with the aid of a validated mathematical model. However, the gap remains.

To understand the behaviour of the polymerization system, most studies so far have focused on the experimental approach. However, this approach is neither reliable nor applicable since its results are heavily dependent on the

${ }^{*}$ Corresponding author: Assoc. Prof. Amir Heydarinasab

Email: a.heidarinasab@srbiau.ac.ir test and laboratory conditions. The other constraint of this approach is the type of catalyst used..$^{3-5}$ Therefore, these studies have not fulfilled the existing gap as defined earlier.

In respect of the modelling, Reginato ${ }^{2}$ modelled an industrial-scale loop reactor using a non-ideal continuous stirred tank model to explain the industrial process, and compared their simulation results with commercial plant data. Al-haj Ali ${ }^{3}$ proposed a generalized model for hydrogen response based on the dormant site theory in liquid propylene polymerization. His research work was based on only experimental data, and there was no validated mathematical model able to predict the polymerization rate profile and the indices of the final product properties simultaneously.

Although some other researchers in this field have carried out their work based on a mathematical model, there remains the defined gap, because their models have been established based on only mathematical calculations without experimental validation. In this context, some studies only tend to focus on loop or fluidized-bed reactors (FBRs), i.e., bulk or gas phase polymerization. ${ }^{2,6-8}$ Yang $^{9}$ has modelled loop propylene polymerization reactors in bulk media. The model was targeted at commercial reactor variables without being attentive to kinetics studies and final product properties. Subsequently, another paper was published involving modelling of multi-scale polypropylene properties in the FBR reactor. Their modelling approach was moment equations. ${ }^{10}$ Like in their in previous work, in $2016 \mathrm{Kim}$ et al. ${ }^{11}$ proposed a simulation for liquid polypropylene polymerization reactors based on Sheripol technology without giving attention to the determination of the vital final product properties, such as average molecular weight and polydispersity. 
In 2018, Varshouee et al. focused on providing a validated model that would be able to predict and plot the polymerization profile. ${ }^{12}$ Their aim was to evaluate the performance of the used catalyst with changing process variables, such as reaction temperature and hydrogen amount in the system, in view point of the kinetic study. Since the profile rate of the polymerization is necessary for determination of the yield $(Y)$ and deactivation constant $\left(K_{D}\right)$ of the catalyst, they explain these matters by a validated model. ${ }^{13}$ They concluded that, according to the Arrhenius theory, an increase in temperature leads to an increase in the polymerization rate. ${ }^{12}$ Regarding the effect of hydrogen on the kinetics, their model showed that increasing hydrogen amount not only increases the rate of polymerization, but also significantly raises the percentage of the activated site on the catalyst. For instance, in the absence of hydrogen, only $10.4 \%$ of the potential active sites are activated for the reaction, while at $18 \mathrm{mg}$ hydrogen content in the system, the percentage of the activated sites of the used catalyst reaches $85.5 \%$. However, the increasing reaction temperature and hydrogen amount have an optimum effect, which should be determined carefully, because above the optimum condition, they have a harmful effect on the catalyst. $^{12-13}$ Consequently, they decided to expand their model to cover the existing gap mentioned previously.

Having that in mind, we attempted to propose a validated model that fulfils these aims, i.e., evaluate the effect of reaction temperature and hydrogen amount on the number and weight average molecular weight $\left(\bar{M}_{n}\right.$ $\& \overline{M_{w}}$ ) and dispersity (Đ) from the product properties viewpoint. By using the results of this study, the catalyst makers will be able to evaluate and improve their catalyst. It also might be attractive and essential for process engineers aiming at replacing new catalyst, increasing plant efficiency, improving product quality, reducing operating costs, and generating new formulation for economical products. Therefore, this study could be applied in basic and applied research. The selected modelling approach is polymer moment balance method (population balance approach) in MATLAB ${ }^{\circledR}$ \& Simulink ${ }^{\circledR}$ software program for slurry polymerization. The model was validated through the experimental data from a lab-scale semi-batch reactor using the $4^{\text {th }}$ generation of Ziegler-Natta catalysts with an acceptable margin of error.

\section{Experimental}

\subsection{Material specifications}

The materials used in this study were as follows. The catalyst used was the $4^{\text {th }}$ generation of spherical $\mathrm{MgCl}_{2}$ supported Ziegler-Natta catalyst containing $3.6 \mathrm{wt} \%$ of $\mathrm{Ti}$; diisobutyl phthalate (DIBP) as internal donor supplied by Sudchemie, Germany. Triethylaluminium (TEAL of $98 \%$ purity) from Merck, Germany, diluted in $n$-heptane was used as a co-catalyst. Cyclohexyl methyl dimethoxy silane (CMDS) purchased from Merck, Germany, was used as an external donor. Polymer-grade propylene was provided from Shazand Petrochemical, Iran. Hydrogen and nitrogen used were of $>99.999 \%$ purity. ${ }^{12-13}$

\subsection{Experimental polymerization procedure}

In this study, slurry homo-polymerization was carried out in heptane media. Polymerization reactor was a one-litre stainless steel vessel manufactured by Buchi. Polymerization set-up was designed in order to conduct slurry polymerization in one vessel. A schematic diagram of polymerization set-up is shown in Fig. 1. A high-pressure $\mathrm{N}_{2}$ line was used to transfer liquid monomer and catalytic system into the reactor.

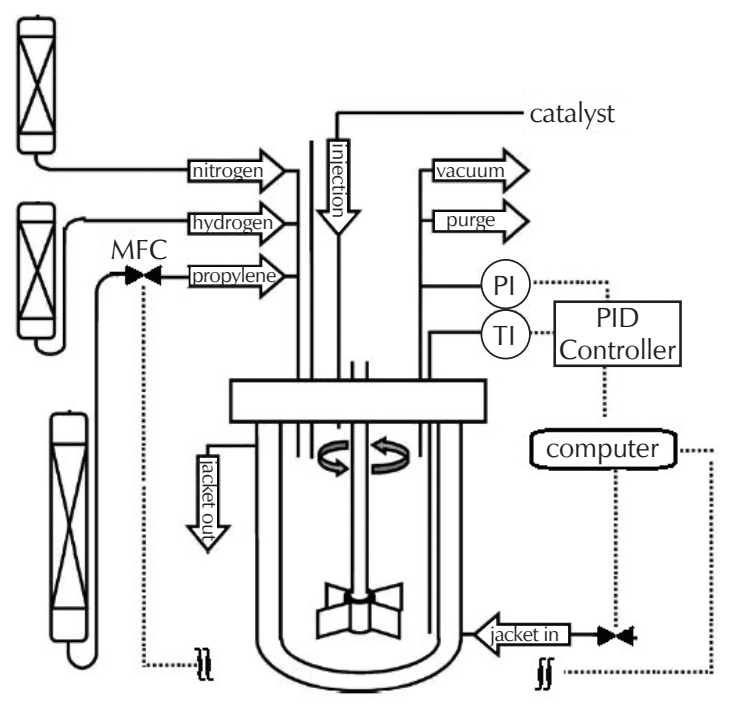

Fig. 1 - Simplified schematic of the reactor system

The catalyst system was injected into the reactor through a stainless steel cylinder under $\mathrm{N}_{2}$ atmosphere. All gases were first purified online by passing through three purification trains (containing molecular sieves) in series. The individual gases were then filtered, and flow of each reactant was measured and controlled with a Mass Flow Controller manufactured by Brooks. Experimental profile polymerization $\left(R_{\mathrm{p}}\right)$ curves come from set-up monitor, the molecular weight of products was measured by gel permeation chromatography (GPC) employing an Agilent PL-220 model with TSK columns at $155^{\circ} \mathrm{C}$ using 1,2,4-trichlorobenzene as a solvent. The GPC was calibrated with the narrow molecular weight distribution polystyrene standard as a reference.

A typical polymerization procedure exists for reactor preparation, polymerization, and discharge. The detailed procedure of the polymerization was according to ref. ${ }^{13}$

\subsection{Mathematical modelling}

\subsubsection{Assumptions}

The following modelling assumptions were considered: (1) Propylene polymerization is carried out in the amorphous phase, and amorphous phase concentration during polypropylene polymerization is at thermodynamic equilibrium condition that obeys that from Sanchez and Lacombe 
equation (SLE) for calculating the amount of the hydrogen molar ratio $\left(x=\mathrm{CH} / C_{m}\right) .{ }^{14}(2) \gamma 1=\gamma 2=\ldots . .=\gamma \mathrm{NC}$, where $\gamma$ is equilibrium constant, and $N C$ is the number of solvent in slurry phase components. ${ }^{2}$ (3) The reaction temperature, pressure, and monomer concentration is kept constant during the polymerization process. (4) The resistance of mass and heat transfer, and the diffusion effect of the reactants is ignored. (5) The propagation constant is independent of the length of the growing polymer chain.

\subsubsection{Mathematical formulas and equations}

In respect to olefin polymerization, kinetics with Ziegler-Natta catalysts might be fairly complicated. ${ }^{2}$ To date, several reaction steps have been proposed in the open literature. ${ }^{2,6}$ The ODE mass balance equations ${ }^{2}$ used in this model were as follows (Eq. 1):

$$
\begin{gathered}
\frac{d C_{j, R}}{d t}=\left[\frac{Q_{\mathrm{f}} C_{j, \mathrm{f}}}{V_{\mathrm{R}}}\right]_{\text {feed(input) }}-\left[\frac{(\eta / \zeta) Q_{0} C_{j, \mathrm{R}}}{V_{\mathrm{R}}}\right]_{\text {output }}+R_{j} \\
\text { where } C_{j, \mathrm{R}}=\frac{\text { mole of } j}{\text { total volume }} \text { for } j=1,2, \ldots, \mathrm{NC} \\
\eta_{j}=\frac{C_{j, \mathrm{a}}}{C_{j, 1}} \text { for } \mathrm{j}=1,2, \ldots, \mathrm{NC} \\
\zeta_{j}=\frac{C_{j, 0}}{C_{j, \mathrm{R}}}=\frac{\rho_{0}}{\rho_{\mathrm{R}}} \cdot D_{\mathrm{f}}, \text { where: }
\end{gathered}
$$

$$
(\eta / \zeta)=\left\{\begin{array}{l}
\eta \text { for liquid phase components } \\
\zeta \text { for solid phase components }
\end{array}\right.
$$

$Q_{f f} Q_{0}$, and $Q_{R}$ are feed volumetric flow rate, reactor-output volumetric flow rate, and volumetric recirculation flow rate, respectively. In Eq. $1, V_{\mathrm{R}}$ and $R_{\mathrm{j}}$ are defined as a reactor volume, and $j$ as component reaction rate.

Since the model is a semi-batch process and constant monomer concentration during the polymerization is assumed, the input and output terms are eliminated $\left(Q_{\mathrm{f}}\right.$ and $\left.Q_{0}\right)$, and therefore the terms $\eta$ and $\zeta$ are meaningless for our study. Table 1 shows possible reactions with their rate equations in the polymerization reactor. The concentration variations with time used in modelling were as follows:

$$
C_{j}=C_{H}, C_{A}, C_{E}, C_{M i}, C_{B}, C_{S}, C_{\text {cat }}, P_{0}^{k}, \mu_{0}^{k}, \mu_{1}^{k}, \lambda_{0}^{k}, \lambda_{1}^{k}, \lambda_{2}^{k}
$$

where $k$ is the site number of the catalyst.

In this study, it was assumed that the catalyst has mono-site, and therefore, $k$ is equal to one. Here, $C_{H}, C_{A}, C_{E}, C_{M i}, C_{B}$, $C_{S}, C_{\text {cat }}$ and $P_{0}$ are the concentrations of hydrogen, co-catalyst (aluminum alkyl), electron donor, monomer, poison, site transfer, catalyst, and potential site in the polymerization, respectively. The component rate equations and moment equations used in the model are listed in Table 2. The final product properties of polypropylene can be estimated

\begin{tabular}{|c|c|c|c|}
\hline Reaction step & Component & Reaction & Rate equation \\
\hline \multirow[t]{2}{*}{ site activation } & hydrogen (1) & $C_{p}+H_{2} \rightarrow P_{0}^{K}$ & $R_{a H}^{K}=k_{a H}^{k} C_{p} C_{H, a}^{O_{a H}^{K}}$ \\
\hline & Al-alkyl (2) & $C_{p}+A \rightarrow P_{0}^{K}+B$ & $R_{\mathrm{aA}}^{K}=k_{a A}^{k} C_{p} C_{A, a}^{O_{a A}^{K}}$ \\
\hline \multicolumn{2}{|c|}{ monomer i (3) } & $C_{p}+M_{i} \rightarrow P_{0}^{K}+M_{i}$ & $R_{\mathrm{aMi}}^{K}=k_{\mathrm{aMi}}^{k} C_{p} C_{M i}^{O_{\mathrm{aMi}}^{K}}$ \\
\hline chain initiation & monomer i (4) & $P_{0}^{k}+M_{i} \rightarrow P_{\delta_{i}, i}^{K}$ & $R_{P 0 i}^{K}=k_{P 0 i}^{k} P_{0}^{K} C_{M_{i}, a}$ \\
\hline chain propagation & monomer j (5) & $P_{n, i}^{K}+M_{j} \stackrel{K p}{\rightarrow} P_{n+\delta_{j}, j}^{K}$ & $R_{P j i}^{K}=k_{P j i}^{k} P_{n, j}^{K} C_{M_{j, a}}$ \\
\hline \multirow[t]{2}{*}{ chain transfer } & hydrogen (6) & $P_{n, i}^{K}+H_{2} \stackrel{K h}{\rightarrow} P_{0}^{K}+D_{n}^{k}$ & $R_{c H i}^{K, n}=k_{c H i}^{k} P_{n, i}^{K} C_{H, a}^{O_{c h i}^{K}}$ \\
\hline & monomer j (7) & $P_{n, i}^{K}+M_{j} \stackrel{K m}{\rightarrow} P_{\delta_{j}, j}^{K}+D_{n}^{k}$ & $R_{c M_{j i}}^{K, n}=k_{c M_{j i}}^{k} P_{n, i}^{K} C_{j, a}^{O_{c M j, i}^{K}}$ \\
\hline \multirow[t]{5}{*}{ site deactivation } & hydrogen (8) & $P_{n, i}^{K}+H_{2} \rightarrow C_{d}+D_{n}^{k}$ & $R_{a H i}^{K, n}=k_{d H}^{k} P_{n, i}^{K} C_{H, a}^{O_{d H}^{K}}$ \\
\hline & & $P_{0}^{K}+H_{2} \rightarrow C_{d}$ & $R_{d H 0}^{K}=k_{d H}^{k} P_{0}^{K} C_{H, a}^{O_{d H}^{K}}$ \\
\hline & Al-alkyl (9) & $P_{n, i}^{K}+A \rightarrow C_{d}+D_{n}^{k}$ & $R_{d A i}^{K, n}=k_{d A}^{k} P_{n, i}^{K} C_{A, a}^{O_{d A}^{K}}$ \\
\hline & spontaneous (10) & $P_{n, i}^{K} \rightarrow C_{d}+D_{n}^{k}$ & $R_{d S p i}^{K, n}=k_{d S p}^{k} P_{n, i}^{K}$ \\
\hline & & $P_{0}^{K} \rightarrow C_{d}$ & $R_{d S p 0}^{K}=k_{d S p}^{k} P_{0}^{K}$ \\
\hline
\end{tabular}
by the moment equations. Evaluating the vital final product properties in this study, i.e., number average molecular weight $\left(\overline{M_{n}}\right)$ and weight average molecular weight $\left(\overline{M_{w}}\right)$ could be calculated by the following equations:

Table 1 - Probable reactions and their rate equations in propylene polymerization used in the model ${ }^{2}$ 
Table 2 - Component rate and moment equations used in the model $^{2}$

\begin{tabular}{|c|c|}
\hline Hydrogen & $R_{H}=-\sum_{K=1}^{N s}\left[R_{a H}^{k}+R_{r H}^{k}+R_{d H 0}^{k}+\sum_{i=1}^{N m} \sum_{n=\delta_{i}}^{\infty}\left(R_{c h i}^{k, n}+R_{d H i}^{k, n}\right)\right]$ \\
\hline Co-catalyst & $R_{A}=-\sum_{K=1}^{N s}\left[R_{a A}^{k}+R_{d A 0}^{k}+\sum_{i=1}^{N m} \sum_{n=\delta_{i}}^{\infty} R_{d i i}^{k, n}\right]-R_{\mathrm{eA}}$ \\
\hline Electron donor & $R_{E}=-\sum_{K=1}^{N s}\left[R_{d E 0}^{k}+\sum_{\substack{l=1 \\
l \neq K}}^{N s} R_{t \in 0}^{k l}+\sum_{i=1}^{N m} \sum_{n=\delta i}^{\infty}\left(\sum_{\substack{l=1 \\
l \neq K}}^{N s}\left(R_{t \in i}^{k, n}+R_{d \in i}^{k, n}\right)\right]-R_{e E}\right.$ \\
\hline Poison & $R_{X}=-\sum_{K=1}^{N S}\left[R_{d X 0}^{k}+\sum_{i=1}^{N m} \sum_{n=\delta_{i}}^{\infty} R_{d x i}^{k, n}\right]-R_{\mathrm{eE}}-R_{\mathrm{eA}}$ \\
\hline Potential sites & $R_{C p}=-\sum_{K=1}^{N s}\left(R_{a H}^{k}+R_{a A}^{k}+R_{a S p}^{k}+\sum_{i=1}^{N m} R_{a M_{i}}^{k}\right)$ \\
\hline Dead sites & 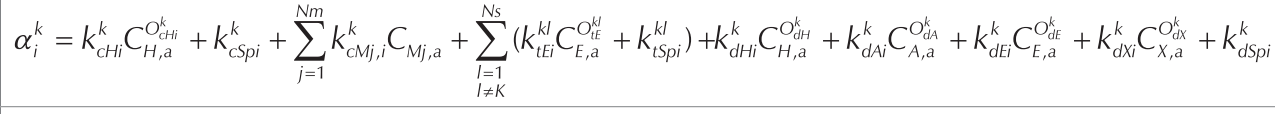 \\
\hline Monomer & $R_{M i}=-\sum_{k=1}^{N s}\left[R_{P 0 i}^{k}+\sum_{j=1}^{N m} \sum_{n=\delta i}^{\infty}\left(R_{P i j}^{k, n}+R_{c M i, j}^{k, n}\right)\right]$ \\
\hline & Moments equations: \\
\hline Live polymer & $R_{p_{n, i}^{k}}=\delta\left(n-\delta_{i}\right)\left[R_{p 0 i}^{k}+\sum_{j=1}^{N m} \sum_{m=\delta i}^{\infty} R_{c M i, j}^{k, m}\right]+\sum_{j=1}^{N m} k_{p i j}^{k} C_{M i, a} P_{n-\delta_{i, j}}^{k}-\sum_{j=1}^{N m} k_{p i j}^{k} C_{M j, a} P_{n, i}^{k}-\alpha_{i}^{k} P_{n, i}^{k}$ \\
\hline Dead polymer & 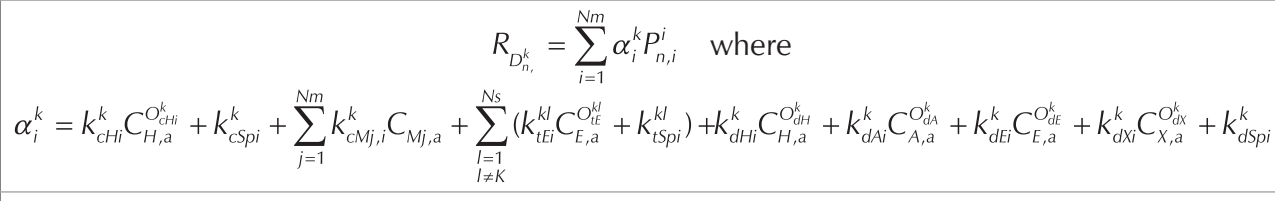 \\
\hline Live moment & $\mu_{\delta_{i, i}}^{k}=\sum_{n=1}^{\infty} n^{\delta_{i}} P_{n, i}^{k}$ \\
\hline Bulk moment & $\lambda_{\delta_{i}}^{k}=\sum_{n=\delta_{i}}^{\infty}\left(\sum_{i=1}^{N m} P_{n, i}^{k}+D_{n}^{k}\right)$ \\
\hline $\begin{array}{l}\text { Zero-order; live polymer } \\
\text { moments }\end{array}$ & $\begin{array}{l}R_{\mu_{0, i}^{k}}=R_{P 0 i}^{k}+\sum_{j=1}^{N m} k_{c M_{i}, j}^{k} C_{M i, a} \mu_{0, J}^{k}-\alpha_{i}^{k} \mu_{0, J}^{k} \\
+\sum_{j=1}^{N m}\left[k_{p i j}^{k} C_{M i, a} \mu_{0, J}^{k}-k_{p j i}^{k} C_{M j, a} \mu_{0, i}^{k}\right]\end{array}$ \\
\hline $\begin{array}{l}\text { First-order; live polymer } \\
\text { moments }\end{array}$ & $R_{\mu_{\delta_{0}}^{k}}=\sum_{i=1}^{N m} \delta(i-l)\left[R_{P 0 i}^{k}+\sum_{j=1}^{N m} k_{c M_{i}, j}^{k} C_{M i, a} \mu_{0, J}^{k}\right]-\sum_{i=1}^{N m} \alpha_{i}^{k} \mu_{\delta_{1, i}}^{k}+\sum_{i=1}^{N m} \sum_{j=1}^{N m} k_{p i j}^{k} C_{M i, a} \delta(i-1) \mu_{0, J}^{k}$ \\
\hline $\begin{array}{l}\text { Zero-order; bulk polymer } \\
\text { moments }\end{array}$ & $R_{\lambda_{0}^{k}}=\sum_{i=1}^{N m}\left[R_{P 0 i}^{k}+\sum_{j=1}^{N m} k_{c M_{i}, j}^{k} C_{M i, a} a_{0, J}^{k}\right]$ \\
\hline $\begin{array}{l}\text { First-order; bulk polymer } \\
\text { moment }\end{array}$ & $R_{\lambda_{\delta, l}^{k}}=\sum_{i=1}^{N m} \delta(i-I)\left[R_{P 0 i}^{k}+\sum_{j=1}^{N m} k_{c M_{i}, j}^{k} C_{M i, a} \mu_{0, J}^{k}\right]+\sum_{i=1}^{N m} \sum_{j=1}^{N m} \delta(i-1) k_{p i j}^{k} C_{M i, a} \mu_{0, J}^{k}$ \\
\hline $\begin{array}{l}\text { Second-order; bulk polymer } \\
\text { moment }\end{array}$ & $R_{\lambda_{2}}=\sum_{K=1}^{N s} \sum_{j=1}^{N m}\left[R_{P 0 i}^{k}+\sum_{i=1}^{N m} k_{c M j, i}^{k} C_{M j, a} \mu_{0, i}^{k}\right]+\sum_{k=1}^{N s} \sum_{i=1}^{N m} \sum_{j=1}^{N m} k_{p j i}^{k} C_{M j, a}\left(\mu_{0, i}^{k}+2 \mu_{1, i}^{k}\right)$ \\
\hline
\end{tabular}

$$
\begin{gathered}
\overline{M_{\mathrm{n}}}=\sum_{K=1}^{N \mathrm{~s}} \sum_{i=1}^{N \mathrm{~m}} \frac{\lambda_{\delta_{i}}^{k}}{\lambda_{0}^{k}} \overline{M_{\mathrm{i}}} \\
\overline{M_{\mathrm{w}}}=\lambda_{2} \cdot \sum_{k=1}^{N s} \lambda_{0}^{k} \overline{M_{\mathrm{n}}} /\left(\sum_{K=1}^{N s} \sum_{i=1}^{N m} \lambda_{\delta_{i}}^{k}\right)^{2}
\end{gathered}
$$$$
\text { then: } Đ=\frac{\overline{M_{w}}}{\overline{M_{n}}}
$$

\subsubsection{Modelling algorithm}

In this study, we outlined the algorithm for programming the mathematical model in a MATLAB ${ }^{\circledR}$ \& Simulink ${ }^{\circledR}$ environment, as shown in Fig. 2A. It is composed of two parts; main-program (named "Runsim") and subroutine (function file). For obtaining kinetic constants in the model, we propose a new approach as iterative method algorithm using consistency property of ODE's equation in Fig. 2B. The advantage of this method is that it is easier and more reliable than conventional methods, i.e., referring directly to open literature or estimating by trial and error. ${ }^{2}$ 
To use the iterative method algorithm, only the initial guess of kinetic constants should be estimated by referring to the open literature. Afterwards, the kinetic constants are adjusted for the catalyst used by the algorithm.

In this study, the initial guess of kinetic constants was estimated and applied to the model from open literature. ${ }^{2,6}$ Then, the constants were exactly adjusted and determined in accordance with the catalyst used in the set-up (experimental data) by the proposed algorithm in Fig. 2B.

\section{Results and discussion}

As outlined in the introduction, in order to cover the defined targets, i.e., evaluate the effect of reaction temperature, hydrogen amounts on the number and weight average molecular weight $\left(\overline{M_{w}}\right.$ and $\left.\overline{M_{n}}\right)$, and dispersity $(\bigoplus)$ from the viewpoint of the product properties, it was necessary to develop our previous work to be suitable in this regard.

The model was coded in MATLAB ${ }^{\circledR}$ \& Simulink ${ }^{\circledR}$ software program, according to the algorithm shown in Fig. 2A. The reaction equation used in the model is listed in Table 1 , and the components rate and moment equation used in the model are summarized in Table 2.

One of the most important advantages of this model is that it is able to show the profile rate of the polymerization graphically, and therefore, it is possible to compare the model profile and the experimental profile rates coming from the lab set-up. By having the profile rate of the polymerization, it is easily possible to study the kinetics of

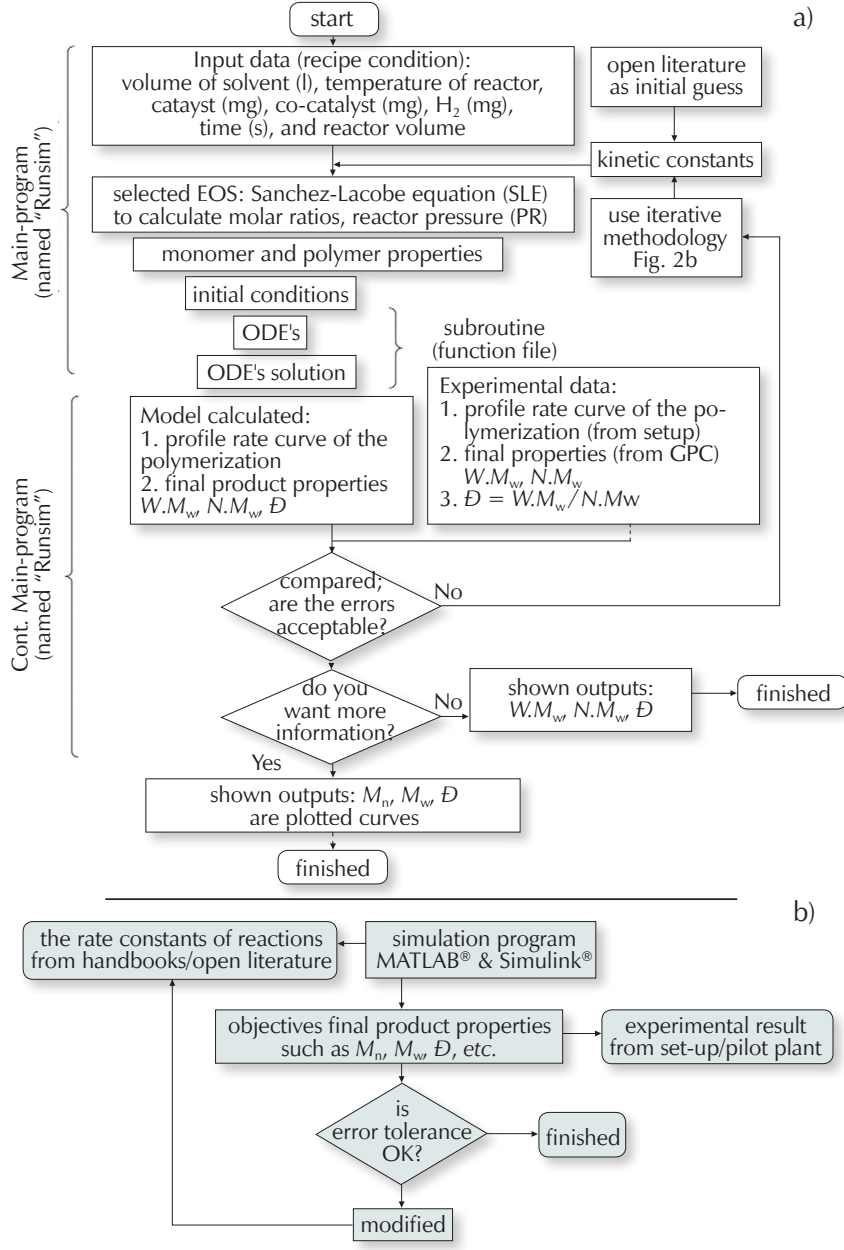

Fig. 1 - (a) General algorithm modelling in this work; (b) Iterative methodology used for adjusting kinetic parameters

Table 3 - Comparison of the model output and experimental results under different conditions

\begin{tabular}{|c|c|c|c|c|c|c|c|c|c|}
\hline \multicolumn{6}{|c|}{ Recipe } & \multicolumn{4}{|c|}{ Results (experimental/model) } \\
\hline $\begin{array}{l}\text { Run } \\
\text { No. }\end{array}$ & $\mathrm{T} /{ }^{\circ} \mathrm{C}$ & $\mathrm{H}_{2} / \mathrm{mg}$ & $\begin{array}{l}\text { Molar ratio } \\
x=\mathrm{CH}_{2} / \mathrm{C}_{\mathrm{m}}\end{array}$ & Catalyst/mg & & $Y / g$ PP & $M_{\mathrm{n}}$ & $M_{\mathrm{w}}$ & 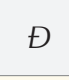 \\
\hline \multirow{3}{*}{1} & \multirow{3}{*}{65} & \multirow{3}{*}{0} & \multirow{3}{*}{0} & \multirow{3}{*}{20} & Experimental result & 63.29 & 210259 & 863057 & 4.1 \\
\hline & & & & & Model result & 65.13 & 205570 & 834523 & 4.06 \\
\hline & & & & & Error ( \% ) & 3 & 2 & 3 & 1 \\
\hline \multirow{3}{*}{2} & \multirow{3}{*}{70} & \multirow{3}{*}{0} & \multirow{3}{*}{0} & \multirow{3}{*}{20} & Experimental result & 72.66 & 304642 & 1134374 & 3.71 \\
\hline & & & & & Model result & 76.4 & 323780 & 1214440 & 3.75 \\
\hline & & & & & Error ( \% ) & 5 & 6 & 7 & 1 \\
\hline \multirow{3}{*}{3} & \multirow{3}{*}{75} & \multirow{3}{*}{0} & \multirow{3}{*}{0} & \multirow{3}{*}{20} & Experimental result & 63.07 & 236154 & 1124367 & 4.76 \\
\hline & & & & & Model result & 67.25 & 270243 & 1178300 & 4.36 \\
\hline & & & & & Error ( \% ) & 6 & 13 & 5 & 9 \\
\hline \multirow{3}{*}{4} & \multirow{3}{*}{70} & \multirow{3}{*}{18} & \multirow{3}{*}{0.00466} & \multirow{3}{*}{10} & Experimental result & 81.33 & 29962 & 144192 & 4.81 \\
\hline & & & & & Model result & 88.4 & 32812.7 & 148874 & 4.54 \\
\hline & & & & & Error ( \% ) & 8 & 9 & 3 & 6 \\
\hline \multirow{3}{*}{5} & \multirow{3}{*}{70} & \multirow{3}{*}{27} & \multirow{3}{*}{0.00703} & \multirow{3}{*}{10} & Experimental result & 74.61 & 24016 & 116939 & 4.87 \\
\hline & & & & & Model result & 76.81 & 24981.1 & 123303 & 4.94 \\
\hline & & & & & Error ( \% ) & 3 & 4 & 5 & 1 \\
\hline
\end{tabular}

$x$ - hydrogen molar ratio is calculated by Aspen Software polymer software based on SLE (SOE) 
the polymerization and determine the crucial indices that belong to the kinetics study. ${ }^{12-13}$

The experimental condition runs are listed under the title "recipe conditions". In addition, the results from the model and experimental are summarized in detail in Table 3.

As shown in Figs. $3 \mathrm{~A}-3 \mathrm{~B}$ and $4 \mathrm{~A}-4 \mathrm{~B}$, the comparison of the polymerization profile rate of the model outputs and the experimental data implies that fairly accurate kinetic constants have been adjusted and applied in the model, meaning that the performance of the designed algorithms for this study, i.e., Figs. 2A-2B are fairly suitable in this study.

From Figs. 3A-3B and 4A-4B, it can easily be concluded that the model performance is acceptable and the existing errors could be justified as follows:

(1) The global error that is the summation of truncation, method, and round off error.

(2) Personal and measurement equipment errors.

(3) The equation of state was selected.

(4) The assumption errors.

As may be seen from Fig. 3A, an increase in temperature increased the rate of polymerization in the absence of hydrogen, while under this condition only $10.4 \%$ of the potential sites on the catalyst were activated. ${ }^{12}$ This phenomenon can easily be explained by Arrhenius theory. In the absence of hydrogen, the best reaction temperature is $70{ }^{\circ} \mathrm{C}$ because maximum yield and minimum deactivation constant $\left(K_{\mathrm{D}}\right)$ of the used catalyst have been observed
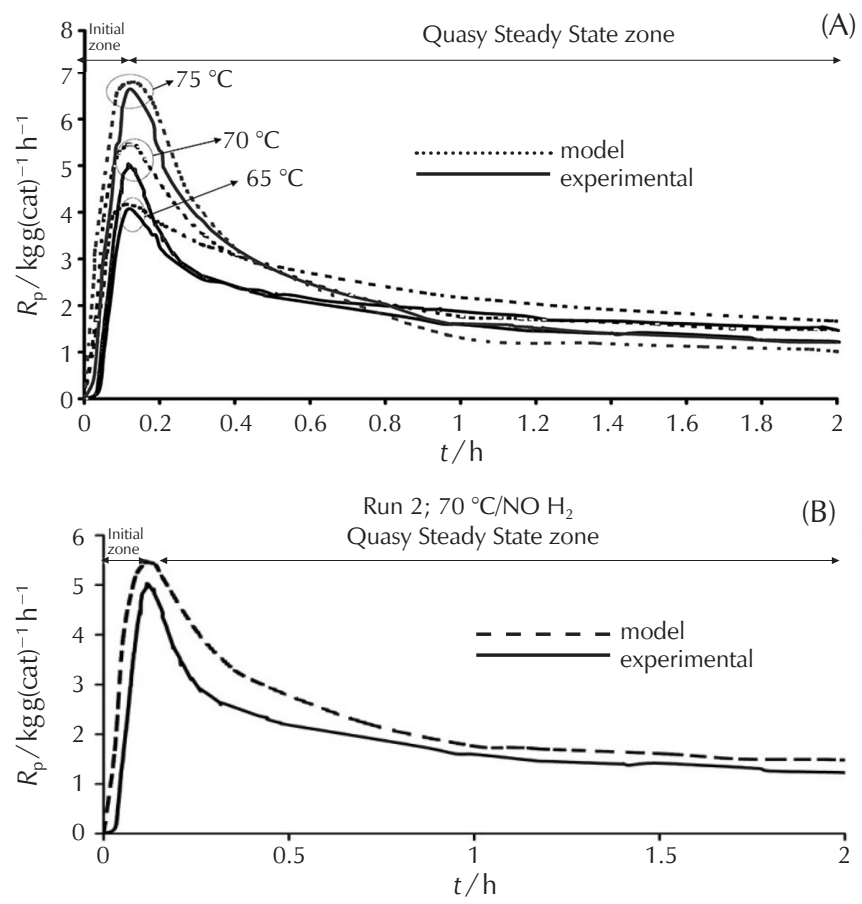

Fig. 3 - Comparison of the experimental and model profile rates in the absence of hydrogen at different temperatures; (A) Runs 1, 2, and 3; (B) Run 2 (optimum temperature) and the model could predict this event properly. ${ }^{13}$ Fig. 5A shows which changes in average molecular weight with temperature follow from a parabolic curve along with a maximum point at $70{ }^{\circ} \mathrm{C}$. Fig. $3 \mathrm{~A}$ shows the comparison of the experimental and model profile rates in the absence of hydrogen at different temperatures, i.e., the optimum temperature condition. In contrast, Fig. 5B shows the variations of dispersity $(\Theta)$ as an indicator of molecular weight distribution, which also has a parabolic curve along with a minimum point at $70{ }^{\circ} \mathrm{C}$. Lower $Ð$ means that molecular weight distribution tends to narrow distribution. This can be justified due to the fact that catalyst has a maximum yield at $70^{\circ} \mathrm{C}$, see Table 3 .

Hydrogen, as chain transfer agent, affects the kinetics of propylene polymerization. Consequently, variations in hydrogen concentration lead to the change in final product properties and activated sites of used catalyst.

Fig. 4B displays the polymerization profile rates at the different hydrogen concentration and in the polymerization system. It shows that increased hydrogen concentration raises the peak, i.e., the presence of hydrogen causes more activated sites of the catalyst to a specific limit. This issue can be justified by dormant site theory. ${ }^{12}$ Above the specific limit, the activated sites of the catalyst are gradually reduced because of the excess hydrogen amounts above the specified limit, as chain transfer agent is able to react with activated sites of the catalyst. Therefore, it is expected that activated sites of the catalyst will be reduced.

These arguments are confirmed by referring and precisely evaluating Figs. 6A-6B, regarding the changes in aver-
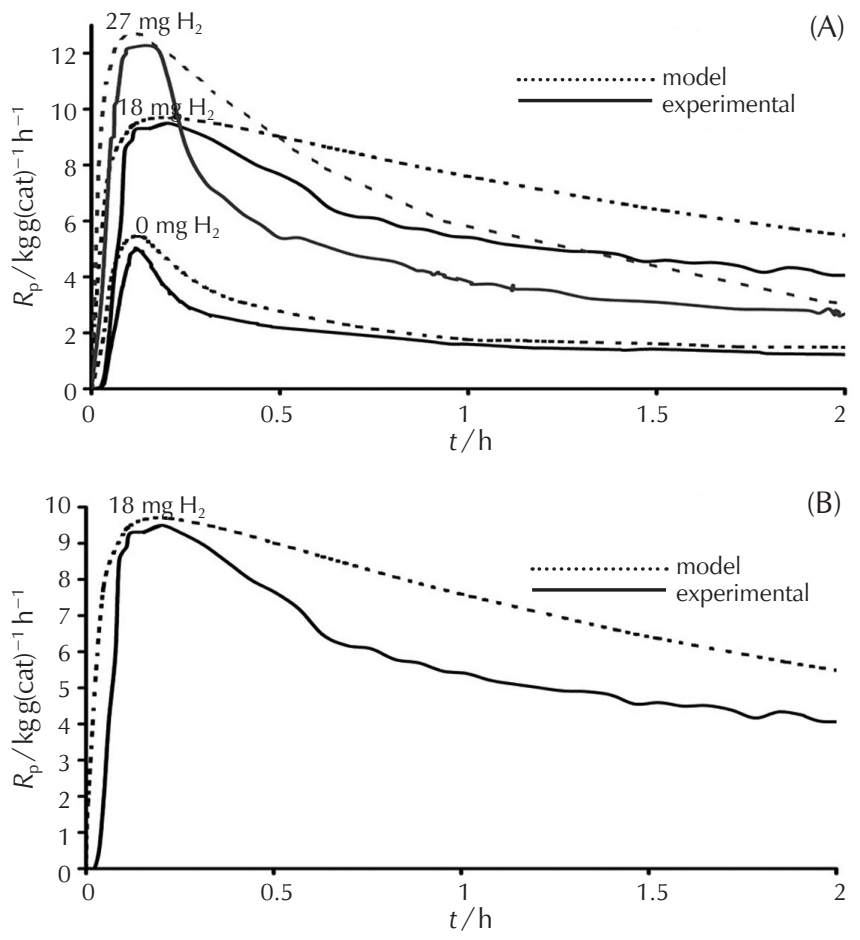

Fig. 4 - Comparison of the experimental and model profile rates at $70{ }^{\circ} \mathrm{C}$ and different hydrogen amounts; (A) Runs 2, 4, and 5, (B) Run 4 (optimum condition) 
(A)

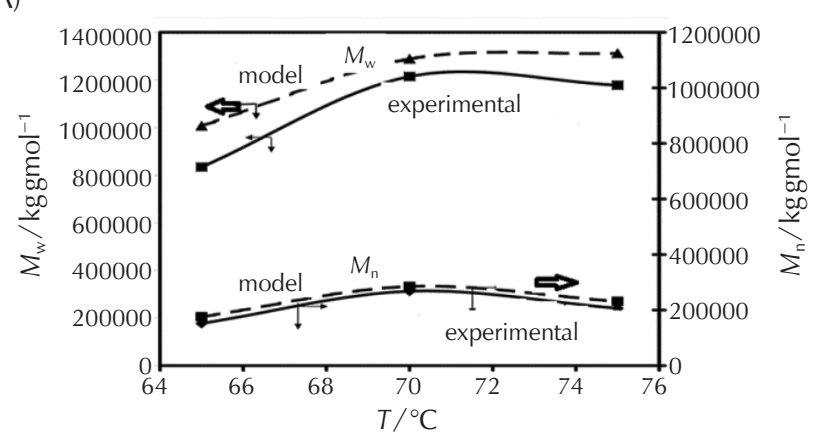

(B)

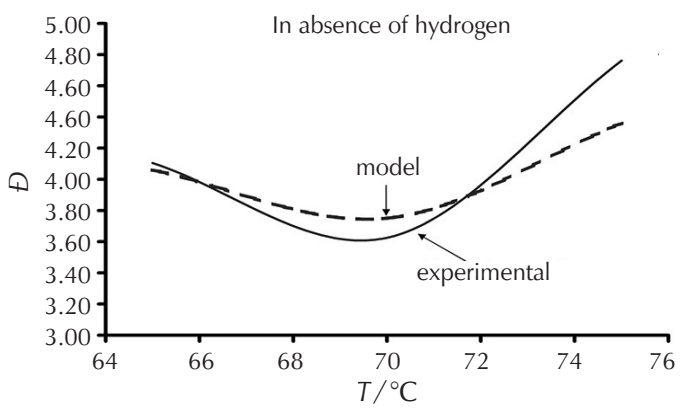

Fig. 5 - (A) Comparison of the experimental and model output $M_{\mathrm{n}}$ and $M_{\mathrm{w}}$ in the absence of hydrogen at different temperatures; (B) comparison of the experimental and model outputs of $\bigoplus$ in the absence of hydrogen at different temperatures

age molecular weight and dispersity $(D)$ with hydrogen amount. It was concluded that in Fig. $6 \mathrm{~A}$, from point $A$ to $B$, the hydrogen role is a chain transfer agent for activating sites on the catalyst. Consequently, the average molecular weight is increased and due to the rapid increase in activated sites by rising hydrogen amount, the number of chains is also increased. Therefore, dispersity $(D)$ has increases according to Fig. 6A. In Fig. 6A after point B, excess hydrogen amount reacts with the active site on the catalyst. As expected, the condition would be reversed, which is clearly shown in Figs. $6 \mathrm{~A}-6 \mathrm{~B}$, thus point $\mathrm{B}$ or $70{ }^{\circ} \mathrm{C}$ and $18 \mathrm{mg}$ hydrogen content (Run 4) could be considered as the optimum condition. Fig. 4A shows the comparison of the experimental and model profile rates in the presence of hydrogen (18 mg) at the optimum temperatures $\left(70{ }^{\circ} \mathrm{C}\right)$. Consequently, Run 4 could be considered the optimum condition in this study.

The significant conclusions in this regard could be listed as follows:

1. If hydrogen concentration is below the optimum condition, by changing the hydrogen concentration, the process engineer could produce a wide range of average molecular weight of the polymer based on the tailor-made product (see Fig. 6A point A to B).

2. At the optimum hydrogen concentration for the polypropylene yield, the minimum average molecular weight is produced.

3. At the above optimum hydrogen concentration, excess hydrogen reacts with the activated site on the used cata-
(A)

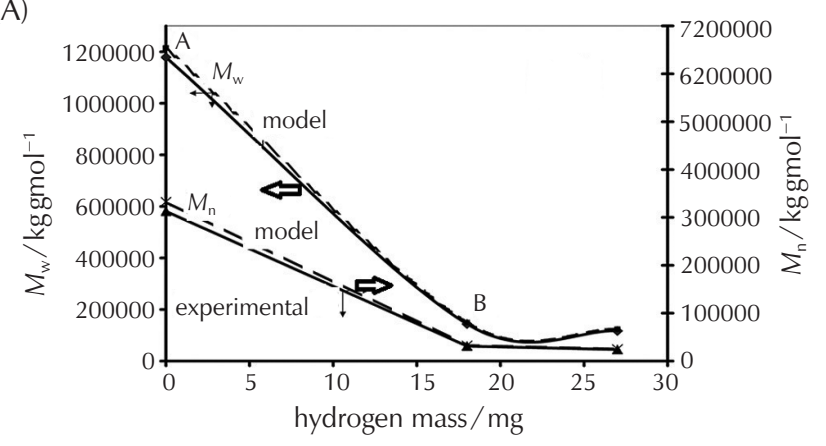

(B)

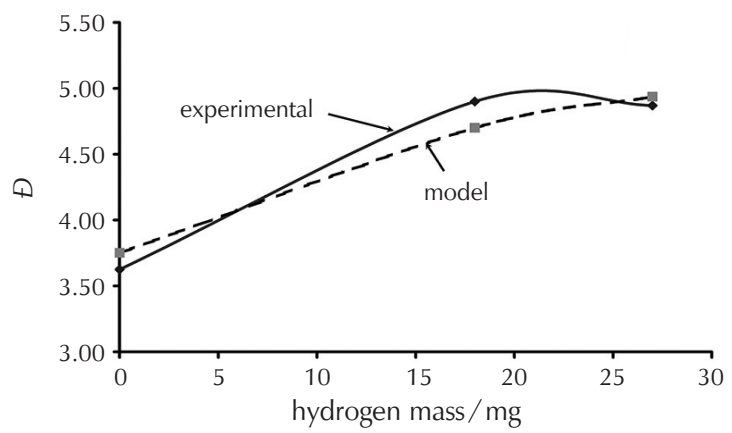

Fig. 6 - (A) Comparison of the experimental and model outputs regarding $M_{w}$ and $M_{n}$, with changing hydrogen amount at $70{ }^{\circ} \mathrm{C}$; (B) comparison of the experimental and model outputs of $€$ in the presence of different hydrogen concentrations at constant temperature of $70{ }^{\circ} \mathrm{C}$

lyst. Therefore, the consumption of the catalyst increases, which is an undesirable event.

4. Existing hydrogen in system generally reduces the average molecular weight. The significance of this issue depends on the process engineer targets.

It is worth emphasizing that the behaviour of each Ziegler-Natta catalyst depends on the user's process conditions and recipe. The novelty in this study is that the proposed model could be able to determine the optimum process conditions based on tailor-made products, replace new catalyst and accessible catalyst with acceptable accuracy.

\section{Conclusion}

The present work aimed to provide a validated mathematical model to predict and evaluate the effect of reaction temperature and hydrogen amount on the number and weight average molecular weight $\left(\bar{M}_{w} \& \bar{M}_{n}\right)$ and dispersity $(Ð)$ from the viewpoint of the product properties. For this purpose, two algorithms were outlined - the first algorithm, i.e., Fig. 2A was used for the main program; and the second algorithm, i.e., Fig. 3A was applied for tuning and adjusting the constants of kinetic equations based on the Ziegler-Natta catalysts. By using the results of this study, the catalyst makers will be able to evaluate and improve their catalyst. In addition, this study might be attractive and essential for process engineers aiming at replacing new cata- 
lyst, increasing plant efficiency, improving product quality, reducing operating costs, and generating new formulation for economical products. Therefore, this study could be applied in basic and applied research. The software program was coded in MATLAB ${ }^{\circledR}$ \& Simulink ${ }^{\circledR}$ and validated by the experimental data from a lab setup reactor.

The comparison of the model outputs and experimental results shows that both results are in accordance with each other in an acceptable margin of error. Finally, it was concluded that the optimum condition in this study was $70{ }^{\circ} \mathrm{C}$ and $18 \mathrm{mg}$ of hydrogen content.

The main aim of this study was to gain a considerable insight into the Ziegler-Natta catalyst performance by changing variables.

\section{List of abbreviations and symbols}

C - total active site concentration, $\mathrm{mol} \mathrm{dm}^{-3}$

$C_{\mathrm{d}}$ - dead-site concentration, $\mathrm{mol} \mathrm{dm}^{-3}$

$C_{j}$ - component $j$ bulk concentration, $\mathrm{mol} \mathrm{dm}^{-3}$

$C_{j, R}$ - concentration into the reactor, $\mathrm{mol} \mathrm{dm}^{-3}$

$C_{k}$ - type $k$ active specie concentration, $\mathrm{mol} \mathrm{dm}^{-3}$

$C_{\mathrm{p}}$ - potential site concentration, $\mathrm{mol} \mathrm{dm}^{-3}$

$D_{k n}$ - dead polymer chain concentration with $n$ monomers originated from site $k, \mathrm{~mol} \mathrm{dm}^{-3}$

$Ð$ - dispersity

$K$ - two-site equilibrium constant, $\mathrm{kg} \mathrm{mol}^{-1}$

$M_{\mathrm{w}}$ - mass average molecular weight, $\mathrm{kg} \mathrm{mol}^{-1}$

NC - number of liquid-phase components

$n_{i, R} \quad$ - moles of component $j$ into reactor

$n_{j, a}-$ moles of $j$ sorbed in the amorphous polymer phase

$n_{j, 1} \quad$ - moles of $j$ in the liquid phase

$N_{\mathrm{m}}$ - number of monomers

$N_{\mathrm{s}}$ - number of sites

$O_{r k}$ - order of reaction $r$ for site $k$

$P_{n, j}$ - growing polymer chain with $n$ monomers with end-group $i$ from site $k$, mol dm ${ }^{-3}$

$P_{0 k} \quad$ - vacant site $k$ concentration, $\mathrm{mol} \mathrm{dm}^{-3}$

$R_{\mathrm{p}} \quad$ - polymerization rate, $\mathrm{kgg}(\text { cat })^{-1} \mathrm{~h}^{-1}$

$R_{\mathrm{p} 0} \quad$ - initial polymerization rate, $\mathrm{kgg}(\mathrm{cat})^{-1} \mathrm{~h}^{-1}$

$t \quad$ - time, $\mathrm{s}$

$T_{\mathrm{r}} \quad$ - reactor temperature, $\mathrm{K}$

$T_{\mathrm{f}} \quad$ - feed stream temperature, $\mathrm{K}$

$V R$ - reactor volume, $\mathrm{m}^{3}$

$Y \quad-$ yield, g PP

$R_{r k, n}-r$ reaction from site $k$ for a growing chain with $n$ monomers, $\mathrm{mol} \mathrm{m}^{-3} \mathrm{~s}^{-1}$

$R_{j} \quad-j$ component reaction rate, $\mathrm{mol} \mathrm{m}^{-3} \mathrm{~s}^{-1}$ $\gamma_{j} \quad$ - equilibrium constant for $j$ component between liquid phase and amorphous polymer phase

$\xi \quad$ - ratio between solid-phase components concentration at reactor output flow and into reactor

$\eta \quad$ - ratio between liquid-phase components concentration at reactor output flow and into reactor

$\chi \quad$ - volume fraction of monomer in the amorphous polymer phase

$\rho_{\mathrm{l}} \quad$ - liquid-phase density, $\mathrm{kg} \mathrm{m}^{-3}$

$\rho_{\mathrm{p}} \quad-$ polymer density, $\mathrm{kg} \mathrm{m}^{-3}$

$\rho_{\mathrm{R}} \quad-$ reactor slurry density, $\mathrm{kg} \mathrm{m}^{-3}$

$\mu_{\delta_{i}, i}^{k}$ - live moment rate equations

$\lambda_{\delta}^{k} \quad$ - bulk moment rate equations

\section{References}

1. V. Busico, R. Cipullo, A. Mingione, L. Rongo, Accelerating the Research Approach to Ziegler-Natta Catalysts, Ind. Eng. Chem. Res. 55 (2016) 2686, doi: https://doi.org/10.1021/ acs.iecr.6b0009.

2. S. Reginato, J. J. Zacca, A. R. Secchi, Modeling and simulation of propylene polymerization in nonideal loop reactors, AIChE Journal 49 (2003) 2642, doi: https://doi.org/10.1002/ aic.690491017.

3. M. Ali, B. Betlem, B. Roffel, G. Weickert, Hydrogen response in liquid propylene polymerization: Towards a generalized model, AIChE Journal 52 (2006) 1866, doi: https://doi. org/10.1002/aic.10783.

4. J. T. Pater, G. Weickert, W. P. van Swaaij, Polymerization of liquid propylene with a $4^{\text {th }}$ generation Ziegler-Natta catalyst-influence of temperature, hydrogen and monomer concentration and prepolymerization method on polymerization kinetics, Chem. Eng. Sci. 57 (2002) 3461, doi: https:// doi.org/10.1016/S0009-2509(02)00213-0.

5. F. Shimizu, J. Pater, W. P. Van Swaaii, G. Weickert, Kinetic study of a highly active $\mathrm{MgCl}_{2}$-supported Ziegler-Natta catalyst in liquid pool propylene polymerization. II. The influence of alkyl aluminum and alkoxysilane on catalyst activation and deactivation, J. Appl. Polym. Sci. 83 (2002) 2669, doi: https://doi.org/10.1002/app.10236.

6. Z. H. Luo, Y. Zheng, Z. K. Cao, S. H.Wen, Mathematical modeling of the molecular weight distribution of polypropylene produced in a loop reactor, Polym, Eng. Sci. 47 (2007), doi: https://doi.org/10.1002/pen.20848.

7. C. Chatzidoukas, J. D. Perkins, E. N. Pistikopoulos, C. Kiparissides, Optimal grade transition and selection of closed-loop controllers in a gas-phase olefin polymerization fluidized bed reactor, Chem. Eng. Sci. 58 (2003) 3643, doi: https:// doi.org/10.1016/S0009-2509(03)00223-9.

8. J. J. C. Samson, P. J. Bosman, G. Weickert, K. R. Westerterp, Liquid-phase polymerization of propylene with a highly active Ziegler-Natta catalyst. Influence of hydrogen, cocatalyst, and electron donor on the reaction kinetics, J. Polym. Sci. Part A 37 (1999) 219, doi: https://doi.org/10.1002/(SICl)109 9-0518(19990115)37:2<219::AID-POLA12>3.0.CO;2-3.

9. X. F. Yang, T. Zheng, L. M. Che, Z. H. Luo, A dynamically distributed reactor model for identifying the flow fields in industrial loop propylene polymerization reactors, J. Appl. 
Polym. Sci. 128 (2013) 4302, doi: https://doi.org/10.1002/ app.38668.

10. Y. P. Zhu, Z. H. Luo, J. Xiao, Multi-scale product property model of polypropylene produced in a FBR: From chemical process engineering to product engineering, Comput. Chem.Eng. 71 (2014) 39, doi: https://doi.org/10.1016/j. compchemeng.2014.07.013.

11. S. H. Kim, S. W. Baek, J. C. Lee, W. J. Lee, S. U. Hong, M. Oh, Dynamic simulation of liquid polymerization reactors in Sheripol process for polypropylene, J. Ind. Eng. Chem. 33 (2016) 298, doi: https://doi.org/10.1016/j.jiec.2015.10.017.

12. G. H. Varshouee, A. Heydarinasab, A. Vaziri, B. Roozbahani, Hydrogen Effect Modeling on Ziegler-Natta Catalyst and
Final Product Properties in Propylene Polymerization, Bull. Chem. Soc. Ethiop. 32 (2018) 371-386, doi: https://doi. org/10.4314/bcse.v32i2.15.

13. G. H. Varshouee, A. Heydarinasab, A. Vaziri, B. Roozbahani, Determining Final Product Properties and Kinetics Studies of Polypropylene Polymerization by a Validated Mathematical Model, Bull. Chem. Soc. Ethiop. 32 (2018) 579-594, doi: https://doi.org/10.4314/bcse.v32i3.16.

14. G. M. N. Costa, S. Kislansky, L. C. Oliveira, F. L. P. Pessoa, S. A. B. Vieira de Melo, M. Embiruçu, Modeling of solid-liquid equilibria for polyethylene and polypropylene solutions with equations of state, J. Appl. Polym. Sci. 121 (2011) 1832, doi: https://doi.org/10.1002/app.33128.

\section{SAŽETAK \\ Određivanje optimalne temperature reakcije i udjela vodika za polimerizaciju propilena matematičkim modelom \\ Gholam Hossain Varshouee, ${ }^{a}$ Amir Heydarinasab, ${ }^{a^{*}}$ Ali Vaziri, ${ }^{a}$ and Seyed Mehdi Ghafelebashi Zarand ${ }^{\mathrm{b}}$}

S obzirom na kinetičku složenost Ziegler-Natta katalizatora u polipropilenskoj polimerizaciji, za sada ne postoji odgovarajući model za određivanje optimalnih uvjeta procesa za predviđanje prosječne molekularne mase i disperzije kao najvažnijih indeksa svojstava konačnog proizvoda. Slijedom toga, razvijen je validirani model koji opisuje odnos između kinetičkog modela i postojećeg jaza pristupom ravnoteže momenata. Zaključeno je da su povišena temperatura reakcije i količina vodika korisni i do određene granice poboljšavaju indekse gotovog proizvoda, ali nakon toga na indekse imaju štetni učinak.

\section{Ključne riječi}

Matematičko modeliranje, polimerizacija propilena, optimizacija, populacijska ravnoteža, prosječna molekularna težina, disperznost

\footnotetext{
${ }^{a}$ Department of Petroleum and Chemical Engineering, Science and Research Branch, Islamic Azad University, Tehran, Iran

${ }^{b}$ Polymer Group, Research and Technology, National Petrochemical Company, Tehran, Iran
}

Izvorni znanstveni rad Prispjelo 1. kolovoza 2018. Prihvaćeno 12. prosinca 2018. 